\title{
Proposta de padronização cartográfica para carta-imagem emergencial de inundação
}

\section{Proposal of cartographic standardization for flood emergencial charter-image}

Guilherme Cardoso da Silva*

Tania Maria Sausen** Andrea Valli Nummer***

\section{Resumo:}

O objetivo deste trabalho foi propor um padrão cartográfico para carta-imagem emergencial de inundação. Assim, foram analisadas cartas-imagem e mapas de inundação, de diversas instituiçôes e de diferentes trabalhos. Também foi elaborado um questionário, aplicado a profissionais que trabalham com mapas de diferentes modos. Percebeu-se que as cartas-imagem e os mapas de inundação se diferenciam significativamente, sendo observadas carências como a falta de elementos, além da não existência de um padrão. Para a elaboração da proposta do presente trabalho foram utilizadas imagens de satélite. Como resultado, esta pesquisa propôs um padrão cartográfico para carta-imagem emergencial de inundação, que procura homogeneizar os mapeamentos de inundação.

\section{Abstract:}

The aim of this work was to propose a cartographic standardization for flood emergencial charter-image. For this purpose, flood charter-image and maps made by different Institutions, and researches were analyzed. A questionnaire was also applied to professionals who work with maps in different ways. It was noticed that the flood charters-image and maps differ on many issues, deficiencies were observed, besides the lack of a standard. For the creation of cartographic standardization satellite images were used. As a result, a proposal of cartographic standardization was made, which aimed the homogeneity of flood charters-image. 


\section{INTRODUÇÁO}

s desastres naturais resultam de eventos adversos que causam grandes impactos na sociedade e são diferenciados principalmente pela sua tipologia, sendo três categorias básicas: Meteorológicos, hidrológicos e geológicos. Os desastres naturais ligados à meteorologia fazem menção a, por exemplo, furacóes, vendavais e granizos. Como exemplo de hidrológicos tem-se estiagens, inundaçóes e geadas e como geológicos, vulcanismos, tsunamis e escorregamentos (TOBIN e MONTZ, 1997).

Apesar de os desastres naturais ocorrerem em qualquer continente, algumas regióes são mais afetadas em funçáo da magnitude e frequência dos fenômenos e da vulnerabilidade de cada sociedade. De acordo com dados entre os anos de 1900 e 2006, o continente asiático foi o que apresentou o maior número de registros. É importante também salientar que dos desastres naturais ocorridos em todo o mundo, $66 \%$ estão atrelados a instabilidades atmosféricas severas, ou seja, presença forte de inundaçóes e tempestades (EM-DAT, 2007; MARCELINO, 2007).

No Brasil, ocorreram 150 registros de desastres no período de 1900 a 2006, os tipos mais frequentes foram as inundaçóes e os escorregamentos. Com relação à distribuição espacial, mais de $60 \%$ dos casos ocorreram nas regióes Sudeste e Sul, sendo importante perceber que são computados no banco EM-DAT somente os desastres considerados de grande severidade (MARCELINO, 2007; EM-DAT, 2007).

Os estudos voltados à identificação, quantificação e cartografia dos desastres naturais são extremamente relevantes para o gerenciamento de riscos. Dentre os eventos causadores de desastres, destacam-se as inundações, vinculadas às instabilidades atmosféricas severas (EM-DAT, 2007). As inundações ocorrem em um número significativo de episódios no mundo todo e tem causado grandes problemas socioeconômicos.

É importante que um evento causador de desastre seja representado cartograficamente, pois isto permite que ele possa ser avaliado de diferentes formas, desde uma análise pós-desastre, em que a cartografia auxilia na compreensão de algumas questôes ou ajuda no resgate (mapa emergencial), até um estudo com um viés mais preventivo, na intenção de evitar o desastre (TOBIN e MONTZ, 1997).

$\mathrm{Na}$ cartografia de pós-desastre deve-se considerar a importância dos mapas emergenciais, pois estes devem representar determinada área, destacando o(s) tipo(s) de desastre(s), com o objetivo de auxiliar na resposta ao fenômeno, resgatando o maior número de pessoas da melhor forma possível, além de prestar as ajudas necessárias. A maioria dos mapas emergenciais são, na verdade, cartas-imagem, que são imagens referenciadas a partir de pontos identificáveis e com coordenadas conhecidas, ou seja, georreferenciadas, podendo conter simbologia e outros elementos fundamentais aos mapas. Comumente são utilizadas imagens de satélite no formato de folhas de carta, em que as cenas de satélites sáo ligadas digitalmente para cobrir a área estipulada (FLEOTIAUX, 1987).

Sabe-se que, para que um mapa, emergencial ou não, possa ser utilizado de forma eficiente, entre outras coisas, ele deve seguir uma padronizaçáo cartográfica, pois desta forma possibilita uma leitura clara e facilita a sua compreensão por parte de quem o estiver utilizando.

No Brasil, existem órgãos que estabelecem normas a fim de padronizar a confecção de mapas, como a Comissão Nacional de Cartografia - CONCAR que faz consideraçóes relativas à elaboração de "Instruçôes Reguladoras das Normas Técnicas da Cartografia Terrestre Nacional".

No ano de 2010, no intuito de reforçar a importância da geração, padronização e armazenamento, acesso, compartilhamento, divulgaçáo, e uso dos dados geoespaciais, foi criada a INDE (Infraestrutura Nacional de Dados Espaciais) que passou a estabelecer normas relativas à Cartografia Nacional e sua produção que deverão ser utilizadas por órgãos e entidades do Poder Executivo Federal (BRASIL, 2009).

Embora haja entidades reguladoras, o que se vê, principalmente em mapas temáticos, é uma falta de padronização, pois as organizaçóes executoras de mapeamentos, em geral, seguem suas próprias regras, vinculadas ao sistema por elas utilizado e que, na maioria das vezes, diferem umas das outras. $\mathrm{O}$ resultado disso são mapas heterogêneos, onde cada organização tem sua maneira de tratar a informação espacial (SANTOS et al., 2010).

A padronização da cartografia é importante para qualquer tipo de mapa, porém para mapas emergenciais é fundamental visto que ele possui certas necessidades que os diferencia dos demais. Dentre essas especificidades, destacam-se a agilidade na geraçáo do mapa e a clareza e objetividade nas representaçóes, pois os mapas serão utilizados por pessoas com diferentes formações, como geógrafos, engenheiros, bombeiros, militares, e até mesmo outros profissionais, como enfermeiros, prefeitos, entre outros. 
Desta forma, este artigo apresenta uma proposta de padronização para cartas-imagem emergenciais de inundação, que tem como objetivo facilitar a sua leitura e interpretação e com isto agilizar as ações em campo na ocasiấo de resgates. A proposta foi elaborada considerando as avaliaçóes e sugestôes de pessoas que se utilizam deste tipo de mapa, bem como de uma análise dos mapas emergências elaborados por diferentes órgáos e instituiçóes. Com isto, pretende-se colaborar com o trabalho de diversos grupos, como a Defesa Civil, Bombeiros, Prefeitura Municipal, entre outros, no momento da resposta ao desastre, pois nem todas as pessoas envolvidas são profissionais ligados à cartografia.

\section{METODOLOGIA}

Inicialmente, para a realização deste estudo, foram utilizados cartas-imagem e mapas de inundação, descritos a seguir:

Cartas-imagem e mapas de inundação do International Charter Space Major Disasters, no total de 21, disponíveis no endereço http://www.disasterscharter. org/home;

Cartas-imagem e mapas de inundação do programa UNOSAT1, no total de 20, disponíveis no endereço http://www.unitar.org/unosat/;

Cartas-imagem e mapas de inundação de outras instituiçóes, programas e projetos, sendo a maioria do Brasil, no total de 20.

As cartas-imagem e os mapas selecionados aqui são de diferentes países e em escalas também distintas. Cabe ressaltar que são todos de inundação, mas nem todos são emergenciais, principalmente os trabalhos do último grupo, intitulado Outros mapas analisados, tendo em vista a dificuldade de se encontrar este tipo de mapeamento realizado no Brasil.

Foi desenvolvido também um questionário enviado a 90 profissionais, com perguntas relacionadas à cartografia, tais como; pontos positivos e negativos de mapas de inundação, opiniōes sobre título, escala, datum, projeção, mapa auxiliar, padronização, posição dos elementos, entre outros fatores.

Inicialmente o questionário apresentou um quadro em que eram solicitadas informaçóes gerais do informante, como o dia em que ele respondeu ao questionário, idade, formação profissional, local do trabalho, função que desenvolve, tempo que trabalha na função, frequência e tipo de mapa que utiliza.

1 O UNOSAT é um programa de tecnologia que fornece análises de imagens e soluçóes de satélite para organizaçóes, visando a ajuda e o desenvolvimento no mundo.
As questôes abordavam a cartografia de inundação de diversas formas, sendo algumas questóes sobre cartografia geral, outras sobre o tema em específico e algumas sobre particularidades do informante.

O questionário, em si, iniciou-se com a apresentação de quatro mapas de inundaçáo, dois obtidos do Disasters Charter (sendo um deles brasileiro), um da UNOSAT e outro retirado de um trabalho realizado no Brasil. A escolha destas cartas-imagem e mapas foi dada devido aos diferentes modos de apresentação, ou seja, eles possuíam diferentes números de informaçōes, cores e posicionamentos. Esta questão pedia ao informante que indicasse qual dos trabalhos, na opiniấo dele, melhor representava o fenômeno de inundação e os motivos que o levaram a esta escolha. A questáo seguinte foi relacionada ao mapeamento escolhido, perguntava sobre os pontos positivos e negativos do trabalho.

A partir de então são apresentadas questôes relativas às cores com que as inundaçóes eram apresentadas, posição dos elementos, título, datum, projeção, escala, norte, legenda, nomenclatura, simbologia, título, mapa de apoio, texto auxiliar, entre outras questóes relacionadas à cartografia de inundação.

Visando a geração de cartas-imagem, utilizaram-se as seguintes imagens de satélite de observação da Terra:

Imagens LANDSAT5/TM, identificada pela órbita 221 , ponto 81 , bandas 3,4 e 5 , de 01 de outubro de 2007 (período de inundação) e 03 de fevereiro de 2007 (período de normalidade), com resolução espacial de 30 metros, obtidas do Catálogo de Imagens do Centro de Dados de Sensoriamento Remoto do Instituto Nacional de Pesquisas Espaciais - INPE, no endereço http:// www.dgi.inpe.br/CDSR/;

Imagens LANDSAT7/ETM+, identificada pela órbita 221, ponto 81 , bandas 3 , 4 e 5 , de 25 de setembro de 2002 (período de inundação) e 23 de julho de 2002 (período de normalidade), com resoluçáo espacial de 30 metros, obtidas do Catálogo de Imagens do Centro de Dados de Sensoriamento Remoto do Instituto Nacional de Pesquisas Espaciais - INPE, no endereço http://www.dgi.inpe.br/CDSR/;

Imagens MODIS, do satélite TERRA, bandas 2, 4 e 7 , de 31 de novembro de 2009 (período de inundaçáo) e 29 de setembro de 2009 (período de normalidade), com resolução espacial de 250 metros, obtidas do Sistema de Resposta Rápida do MODIS (MODIS Rapid Response System), no endereço http://rapidfire. sci.gsfc.nasa.gov/subsets/.

Foi utilizado o software Excel, para a tabulação 
dos dados e elaboração de gráficos, tanto dos mapas analisados quanto dos questionários que foram aplicados; ArcGIS 9.3 para a realização das composiçóes coloridas; AutoCAD 2008 para georreferenciamento das imagens e extração das temáticas e CorelDraw X3 para a edição final dos mapeamentos.

O International Charter Space Major Disasters é um acordo internacional entre agências espaciais para apoiar, com dados e informaçôes espaciais, os esforços de ajuda em caso de eventos de emergências causados por grandes desastres, tendo o objetivo de melhorar a eficácia e a organizaçáo das operaçóes de socorro nas regióes afetadas, prevenir acidentes e aperfeiçoar a reconstrução das infraestruturas destruídas por grandes desastres. Assim, o Charter objetiva proporcionar um sistema unificado de aquisição e liberação de dados espaciais para aqueles países afetados por desastres naturais ou causados pelo homem (http://www.disasterscharter.org).

Cada Agência Membro se compromete a oferecer recursos para apoiar o compromisso de prover dados espaciais ao Charter e desta forma auxiliar a mitigar os efeitos causados pelos desastres.

É interessante salientar que o Disasters Charter trabalha mais especificamente com mapas emergenciais, fazendo um trabalho bastante importante, que atende todo o mundo.

Os mapas presentes no endereço eletrônico http://www.disasterscharter.org, do International Charter: Space and Major Disasters, são muitas vezes realizados com o apoio do UNOSAT-UNITAR (United Nations Institute for Training and Research), que é um programa que realiza análises de imagens de satélite e desenvolve soluçóes de pesquisa para dentro e fora do sistema das Naçôes Unidas para ajudar áreas críticas, com auxílio humanitário, segurança, ordenamento do território e desenvolvimento estratégico. Assim, foram utilizados diversos mapas, 21, particularmente deste órgão para realização de análises para este trabalho (http:// www.unitar.org/unosat/).

Salienta-se que a maioria dos trabalhos retirados do UNOSAT é de regióes do Paquistão. Isso se deve ao fato de haver um grande número de mapas de inundaçáo realizados nesse país e encontrados no site deste órgão. Este país enfrenta inundaçóes com expressiva frequência, além do significativo número de pessoas afetadas.

É interessante salientar que os trabalhos foram analisados de forma padronizada, por meio dos mesmos pontos de análise, e após uma observação dos trabalhos de inundação, juntamente com pesquisas bibliográficas, foram elencados os pontos de análise, para que fosse possível avaliá-los de forma coerente.
Os itens analisados foram os seguintes: Título, legenda, escala, datum, projeção, coordenada, simbologia, nomenclatura, cores, indicação de Norte, apresentação de mapa em escala menor e texto complementar.

Optou-se pela elaboração de um questionário, que é um método bastante utilizado na coleta de dados, onde o respondente pode se valer do anonimato, o que permite que as respostas correspondam mais fielmente ao que ele realmente pensa sobre o tema (PARRA e SANTOS, 1998).

A elaboração das perguntas para o questionário se baseou na literatura que trata de normas, elementos cartográficos e inundação; nas análises dos trabalhos de inundação e até mesmo em discussões com pessoas da área. Após a seleção das perguntas e finalização do questionário, houve a aplicação à profissionais de locais onde o mapa de inundação é de fundamental importância, como Defesa Civil, Exército, bombeiros, universidades e instituiçóes, com a finalidade de avaliar como estas pessoas veem os mapas, e quais as carências apontadas por eles. Essas questōes colaborararam na elaboração de uma legenda padronizada para mapas de inundação. É válido destacar que os informantes são das mais diversas áreas, o que enriquece a pesquisa de forma significativa, pois fornece visôes bastante distintas no que tange a mapas de inundação.

Visando um bom controle desta etapa, criou-se um endereço eletrônico (guilherme.ppggeo@gmail. com), e os e-mails foram enviados individualmente, na tentativa de evitar que eles fossem considerados spams pelo sistema.

Foram enviados 90 questionários, tendo retorno de apenas 33. Após a aplicação dos questionários, houve a tabulação dos dados. No caso de perguntas fechadas (objetivas), foi realizada de forma direta, onde cada coluna representa uma alternativa. Já para perguntas abertas (discursivas), foi realizada uma análise das palavras mais frequentes que representaram a opinião do informante.

Concluída a fase de coleta das cartas-imagem e dos mapas e da aplicação dos questionários, foi realizada a tabulaçáo dos dados no software Excel, onde foram criadas tabelas com diferentes elementos. As cartas-imagem e os mapas foram tabulados de acordo com os pontos de análise já citados no presente trabalho, retirados das três fontes utilizadas (Disasters Charter, UNOSAT e Outros mapas analisados), e os questionários de acordo com cada questão apresentada.

$\mathrm{Na}$ análise foi empregada a estatística descritiva, onde a realidade observada é descrita com a utilizaçáo de métodos numéricos e gráficos. Este último foi empregado para apresentar de modo mais claro o resultado en- 
contrado na tabulação dos dados (PIRES, STRIEDER e DAL'ASTA, 2011).

A partir disso, foi realizada uma integração dos dados, ou seja, uma avaliação dos resultados obtidos a partir do questionário, juntamente com os resultados das avaliaçóes dos mapas de diferentes instituiçôes. Isso foi possível dada à compatibilidade das questôes apresentadas no questionário, com os pontos julgados relevantes na análise das cartas-imagem e dos mapas. Assim, pode ser realizada uma comparação entre as respostas dos entrevistados relativas a determinado assunto, e confrontar com o que se viu na realidade dos mapeamentos dentro dessa mesma questáo. Isso foi de fundamental importância na pesquisa, pois ditou o grau de proximidade entre os mapas e o ideal dos informantes.

Para a elaboração da proposta, foi utilizada como área teste, a área da regiáo metropolitana de Porto Alegre e baixo curso do rio Jacuí. Para a primeira carta-imagem desenvolvida, foi utilizada uma imagem LANDASAT-5/TM, órbita 221 , ponto 81 , da área teste, do dia 01/10/2007. Após uma análise desta imagem, percebeu-se a necessidade de se obter outra, de uma data distinta e sem inundação, para delimitar o rio em seu período de normalidade e no período de inundação, realçando assim a área inundada. A imagem escolhida foi a do dia 03/02/2007.

Assim, utilizando-se o software ArcGIS, atribuiu-se a cor azul a banda 3, verde a 4 e vermelha a 5 , tendo como resultado composição colorida, onde, basicamente, a água ficou representada pela cor azul, e área urbana com um tom de rosa/roxo, a vegetação de verde e o solo exposto em rosa. Este processo foi realizado de forma idêntica em ambas as datas.

Após a elaboração da composição colorida, utilizou-se o software AutoCAD para georreferenciamento, em que foram coletados cerca de 20 pontos base. Em seguida, com o georreferenciamento realizado, utilizou-se a ferramenta polyline para destacar as temáticas.

Por fim, com todas as temáticas julgadas relevantes sendo evidenciadas, utilizou-se o software CorelDRAW para a arte final. Neste momento ajustaram-se as cores e foram colocados alguns detalhes, como informaçóes da carta-imagem, escala, um pequeno texto auxiliar, mapa de apoio, informaçóes de rodovias (BRs e $\mathrm{RSs}$ ), cidade principais, aeroportos, rodoviárias, nomes de rios, lagos, lagunas e lagoas, pontes entre outros detalhes, dependendo da necessidade da carta-imagem de acordo com sua escala.

Após a elaboração da primeira carta-imagem, na escala de 1:100.000, percebeu-se a necessidade de traba- lhar com outras escalas, a fim de apresentar a padronização a qual se prpóe a presente pesquisa em outras realidades, e observar quais alteraçôes e informaçóes seriam necessárias nestas outras cartas-imagem.

Para isso, utilizaram-se imagens LANDSAT-7/ ETM+, para a elaboração de uma carta- imagem de escala maior. Este segundo mapa foi elaborado na escala 1:40.000, com um recorte da regiáo específica da primeira carta-imagem, que é a regiáo metropolitana de Porto Alegre - RS.

Para este trabalho, seguiram-se os mesmos preceitos do primeiro, com pequenas alteraçóes devido as suas particularidades, tais como nome de avenidas principais, além de BRs e RSs, localização de Prefeitura, quartel de bombeiros e escolas.

Após a realização desta segunda carta-imagem, decidiu-se elaborar um terceiro trabalho, desta vez em uma escala pequena, a fim de mostrar como esta proposta cartográfica para carta-imagem emergencial de inundação seria apresentada neste tipo de escala. Para sua elaboração utilizou-se imagens MODIS, abrangendo todo o Estado do Rio Grande do Sul, referente à inundação do dia 29/11/2009, e outra relativa ao período de normalidade dos rios, do dia 31/09/2009.

O processo de elaboração desta proposta de padronização cartográfica foi o mesmo utilizado nas cartas-imagem com as imagens LANDSAT, com exceção das bandas utilizadas, que neste caso foram as bandas 7 (R), 2 (G) e 4 (B), e das particularidades exigidas por uma carta-imagem em escala pequena, 1:500.000.

\section{RESULTADOS E DISCUSSÓES}

\section{Análise Das Cartas-Imagem E Dos Mapas De Inun- daçáo E Aplicaçáo De Questionários}

No Brasil poucos mapas emergenciais são elaborados, e a maioria deles é gerado com imagens do Google Earth, que não possuem boa precisão (LOPES, 2009). Por esta razáo, não havia muitos mapas e cartas-imagem emergenciais do Brasil para comparar com os do Disasters Charter e do UNOSAT.

Foram analisados mapas de diversos locais do mundo e em diferentes idiomas, havendo muitas vezes também alguns percalços na análise de alguns mapas, já que por algumas vezes estes eram tão incompletos, que dificultavam as constataçóes, deixando dúvidas se eram mesmo mapas de inundação, pois muitos são tratados como meras figuras e não apresentavam quesitos básicos como título e legenda, além de outros elementos, como 
datum, projeção e escala que também eram muitas vezes negligenciados.

Contatou-se que muitos mapas possuem carências quanto aos elementos apresentados. Percebeu-se que náo há um padrão quanto à cartografia de mapas de inundação, já que foram observados trabalhos bastante distintos desta temática.

Percebeu-se que, de forma geral, as consideraçóes feitas pelos informantes vão ao encontro do que as normas cartográficas estipulam. Deste modo, há uma facilidade quanto à conciliação de uma padronização cartográfica para mapas e cartas-imagem de inundação e o seu público.

Por algumas vezes os informantes se contradizem, já que acreditam estar satisfeitos com a cartografia de mapas de inundaçáo, mas quando questionados separadamente sobre alguns elementos, mostram-se bastante críticos.

De acordo com as respostas do informantes, ficou evidente as carências existentes no mapas de inundação, como falta de padrão de cores, denominaçôes e informaçóes, elementos que dificultam a compreensão do material.

Ficou evidente que a maioria dos informantes considerou a cor azul a melhor para ser utilizada na representação de inundaçôes, o que apesar de ser uma convenção na cartografia topográfica, muitas vezes não é respeitada, pois como a inundação é um fenômeno, e não simplesmente um corpo d'água, como lago, laguna, lagoa, açude, rio, mar e oceano (comumente representados na cartografia tradicional), observa-se a utilização de outras cores.

Ainda quanto à padronização, a maioria dos informantes alegou que se as posiçóes dos elementos obedecessem a uma norma, ou seja, todos os mapas de inundação fossem apresentados com os mesmos dados e nos mesmos locais, a leitura seria facilitada. Também a maioria dos informantes foi favorável à padronização do termo utilizado, por exemplo, "Área Inundada", com a finalidade de trazer uniformidade à terminologia.

Os informantes se mostraram favoráveis as normas ao indicarem, em sua grande maioria, 79\%, que os títulos dos mapas devem ser completos, possuindo indicação do fenômeno que é representado $(\mathrm{O}$ quê?), onde ocorreu (Onde?) e a data da ocorrência (Quando?).

Ficou bastante evidente a relevância, conforme os informantes, da utilização de mapas de apoio para colaborar no entendimento do local. Neste mes- mo sentido, foi comentada a importância da utilizaçáo de elementos básicos da cartografia, que por vezes não são utilizados, como escala, Norte, datum, projeção, coordenadas e textos auxiliares.

Percebeu-se também uma grande preocupação quanto à clareza e objetividade dos mapeamentos, sendo citada pelos informantes a importância de um equilíbrio nos trabalhos, ou seja, que dependendo da escala fossem adotadas as medidas necessárias para não resultar em um mapa com excesso ou carência de informaçóes, visto que qualquer uma dessas situaçóes seria negativa para o leitor do mapa.

Sendo assim, percebe-se uma grande insatisfação por parte dos informantes com relação à cartografia de mapas de inundação. Salienta-se assim a relevância desta situaçáo, visto que foram avaliadas as opinióes de diversos tipos de profissionais, em diferentes funçôes e fases de suas carreiras, que foram de fundamental importância para a posterior elaboração das legendas para catas-imagem de inundação.

\section{Proposta De Padronizaçáo Cartográfica Para Carta- -Imagem Emergencial De Inundaçáo}

Levando em consideraçáo todos os pontos de análise utilizados para avaliar os mapas de inundação encontrados em grandes instituiçóes, dissertaçóes e teses, além do questionário aplicado à profissionais que trabalham de alguma forma com mapeamentos, e da literatura voltada à cartografia, propôs-se um mapa padrão de inundação, que obedeça aos preceitos vistos até então.

Para a elaboração do mapa, inicialmente se levou em consideração a Norma para Desenho Técnico - ABNT NBR 10647, que apresenta as margens necessárias de acordo com o tamanho da folha utilizada. No caso deste trabalho, sendo utilizado o formato A4, as margens devem ser de $25 \mathrm{~mm}$ à esquerda, e $7 \mathrm{~mm}$ à direita. É válido salientar que este espaço maior à margem esquerda existe para a necessidade de perfuraçáo para arquivamento, (ABNT, 1987).

Outro ponto encontrado nos trabalhos foi a falta de compatibilidade entre a coordenada apresentada e como ela era exposta no mapa. Assim, tomou-se cuidado de usar linhas que representassem as coordendas X e Y, em caso de coordenadas UTM, ou marcadores de interseção de linha, caso fossem utilizadas coordenadas geográficas. Na prática também é comum que o profissional indique o uso de do tipo de coordenada, mas no trabalho utilize outro. Como exemplo disso, tem-se a Figura 1. 
a)

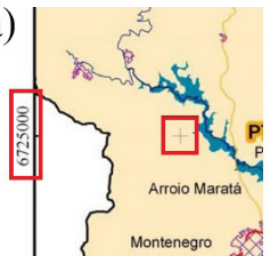

b)

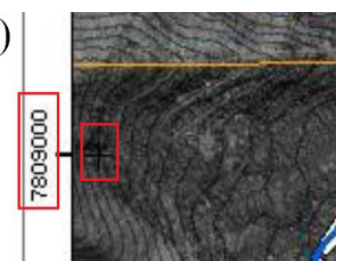

Figura 1 - Exemplo de mapas que utilizaram de coordenadas UTM com marcadores de geográficas

O ponto que exigiu maior cuidado foi a legenda, que além de ajudar na leitura do que é apresentado no mapa, ainda traz a necessidade de bastante atenção por parte do profissional que a elabora, pois é preciso decidir a colocação ou não de algum elemento. Dependendo da escala, da necessidade, alguns descuidos podem diferenciar um trabalho bastante completo de um com excesso de informaçóes, ou um mapa objetivo de um carente de informaçôes.

A proposta de padronização cartográfica do presente trabalho visou utilizar a apresentação de rodovias e diferenciá-las, localizar as sedes dos principais municípios e também possíveis aeroportos existentes na imagem, dados necessários em mapas de inundação, e dependendo da escala utilizada, elementos como cidades principais, aeroportos, rodoviárias, rodovias (BRs e $\mathrm{RSs}$ ), bombeiros, escolas, etc., que são de fundamental importância pois auxiliam a Defesa Civil e outros grupos em suas ações nas emergências.

Portanto, foram elaboradas três legendas cartográficas bastante semelhantes, ou seja, seguindo um padrão quanto à elaboração, com algumas variações de acordo com a escala adotada. Isso foi feito para apresentar a proposta de carta-imagem de inundação em diferentes situações, com escala média e pequena, havendo então uma diferença no nível de detalhes e na abrangência do mapeamento quanto à área.

Quanto à legenda, de forma geral, foi adotada a cor azul para os corpos d'água, conforme a norma de cartografia, com pequenas variaçóes de tom, de acordo com o que a cartografia brasileira adota nas cartas topográficas e também levando em consideração o que os informantes indicaram nos questionários.

Assim, o curso de água em seu período de normalidade foi representado pela cor azul escuro, e a inundação em um tom de azul mais claro. Conforme os resultados do questionário, esta seria a melhor forma de representar a inundação. Para os açudes, lagunas, lagoas e lagos, foi utilizado um tom ainda mais claro de azul, se diferenciando tanto da inundação, quanto do curso normal dos rios. Isso foi relevante até mesmo para dis- tinguir estes corpos d'água de suas próprias inundaçóes.

A variação nos tons de azul da representação das águas, de forma geral, seguiu as normas cartográficas. Foram atribuídos valores do RGB (red, green e blue) no software de arte final CorelDRAW. Para todas as cartas-imagem geradas neste trabalho, os valores do RGB dos cursos normais dos rios foram R(40), G(22) e B(111), e para a área inundada, esses valores foram $R(0), G(147)$ e B(221).

A legenda também destaca outros elementos, como área urbana, vegetação, solo exposto e até mesmo areia, caso estivessem presentes. Esta primeira parte da legenda serve como base, auxiliando na primeira observaçáo, utilizando cores para facilitar a leitura e consequente interpretação dos elementos.

A partir de então, foram incorporados outros elementos importantes da área escolhida. Para isso destacou-se as cidades, rodovias (nacionais e estaduais), pontes, rodoviárias e aeroportos. Estes elementos foram representados à medida que a escala permitia, ou seja, se o nível de detalhamento era compatível com a dimensão do elemento, e se havia tal situação no local escolhido. Desta maneira, alguns elementos podem estar presentes em um mapa e não estar em outro, ou pode estar presente em ambos, mas de forma diferenciada, estando esta questão no campo da Generalização cartográfica.

Estes elementos, da segunda parte da legenda, foram escolhidos pois são importantes para mapas emergenciais. Estes são mapas emergenciais de resposta, ou seja, que são utilizados para atuar em campo, compondo cerca de $90 \%$ dos mapas de inundação, e é para este tipo de trabalho que a proposta de padronização da presente pesquisa foi elaborada.

Temas como vias de acesso (estradas e rodovias), serviços (bombeiros, escolas, aeroportos, postos de saúde e hospitais, ), entre outros, são importantes para mapas emergenciais, já que muitas vezes, apesar de serem utilizados por pessoas que sabem ler mapas, eles não necessariamente são profissionais da área de cartografia. Portanto a legenda precisa ser clara, objetiva e de fácil entendimento, apresentando temáticas ou elementos que facilitem o trabalho do profissional que está em campo e atuando em situaçóes de emergência, como resgate e salvamento, sem que haja desperdício de tempo.

Os elementos foram considerados importantes ou náo, de acordo com a bibliografia voltada a mapas, normas cartográficas, trabalhos anteriormente realizados e as respostas dadas pelos informantes no questionário.

Concluindo a etapa da legenda, foram destacados outros elementos importantes, tais como, escala, datum utilizado e projeção, que por muitas vezes são 
esquecidos nos mapas de inundação, conforme avaliado. A escala foi destacada, pois permite ao leitor saber quantas vezes a realidade foi reduzida para ser apresentada no mapa, o datum, pois indica o ponto de referência a partir do qual a representaçáo dos paralelos e meridianos (e todo o restante) está relacionado, já que diferentes data são baseadas em modelos matemáticos distintos, e a projeção por esclarecer como a realidade foi projetada e como as distâncias, áreas e formas foram representadas.

Conforme o que foi constatado na pesquisa com as cartas-imagem e mapas de inundação e também no que foi dito pelos informantes nos questionários, julgou-se relevante um mapa auxiliar, em escala menor, que colaborasse para uma visualizaçáo do local de forma mais ampla. Assim, confeccionou-se um pequeno mapa do Rio Grande do Sul, destacando a área trabalhada em pequena escala.

Também conforme os dados levantados indicaram, foi incluído um pequeno texto auxiliar com as seguintes informaçóes: como o mapa foi confeccionado, fonte e datas das imagens, identificação do elaborador e a data em que o mapa em foi elaborado.

Por fim, no próprio mapa, foram indicados todos os pontos citados na legenda, além dos nomes das cidades, rios principais, escala, coordenadas geográficas, devido a maior facilidade na utilização em campo (principalmente para profissionais não especializados) e logotipos.

Foi escolhida a região metropolitana de Porto Alegre e o baixo curso do rio Jacuí para serem elaborados os dois primeiros mapeamentos. Este município fica às margens do Lago Guaíba de Oeste a Sul, ainda compreendendo os rios Gravataí, dos Sinos, Jacuí e Caí. Ainda destacam-se alguns arroios, tais como: Feijó, Cavalhada, do Salso, das Graças, do Lami, da Taquara, Chico Barcelos e Dilúvio. Fez-se então uma composição colorida, com as bandas $5(\mathrm{R}), 4(\mathrm{G})$ e 3(B), do satélite LANDSAT-5/TM disponíveis na página do DGI-INPE. Esta imagem representou a data da inundação, ou seja, a partir dela foi extraída a temática de áreas inundadas, além de ser a imagem base do primeiro mapeamento.

Para se ter um parâmetro do curso normal das águas deste local, foi solicitado ao DGI-INPE as imagens também LANDSAT-5/TM do dia 03/02/2007, que foi a data mais próxima com pouca interferência de nuvens. Destas imagens, também foram selecionadas as bandas 5 , 4 e 3 e realizada uma composiçáo colorida (5 $43 \mathrm{RGB}$ ) por meio do software ArcGIS.

Depois de realizada a composição colori- da, foi retirado o curso normal das águas na data de 03/02/2007, e colocadas sobre a imagem de data posterior, 01/10/2007, utilizando o software CorelDRAW X3. Deste modo foi possível comparar os cursos d'água nas diferentes datas, com e sem inundação.

Cabe salientar que o software CorelDRAW X3 foi utilizado para edição final, ou seja, para deixar o mapeamento o mais apresentável e claro possível e foi tomado cuidado quanto às normas, pois o objetivo do presente trabalho é, fundamentalmente, propor um padrão cartográfico para cartas-imagem de inundação. A escolha desse software se deu devido a náo se estar analisando o fenômeno de inundação em si (para isso poderia ter sido adotado um SIG), mas sim para propor um padrão para mapeamentos de inundação, ou seja, foi feita uma simulação.

A escolha das bandas 5, 4 e 3 para a composição colorida se deu conforme informaçóes verificadas no site do DGI-INPE, pois se trata de uma composição que mostra mais claramente os limites entre solo e água, permitindo discriminar bem a vegetação. Desta forma, a extração das temáticas a partir de aplicativos, como SIGs e sistemas de processamento de imagens, fica relativamente fácil para o profissional editor cartográfico.

As imagens do LANDSAT-5/TM possuem uma resolução espacial de 30 metros, ou seja, cada pixel da imagem representa um quadrado no solo com o lado igual a 30 metros, com exceção da banda 6 , mas esta não foi utilizada.

Como dito anteriormente, a proposta de padronização cartográfica para carta-imagem emergencial de inundaçáo elaborada visou estar de acordo com o exposto pelos profissionais respondentes e teve como base as observaçóes de trabalhos do Disasters Charter, UNOSAT e mapas retirados de trabalhos afins. Mas não se pode deixar de seguir algumas normas, havendo um equilíbrio entre a liberdade do profissional que elabora o mapa e as regras que norteiam os mapeamentos.

Expostos todos estes pontos, apresenta-se a primeira proposta de padronização cartográfica para carta-imagem de inundaçáo, em escala média, semi-detalhe, de 1:100.000, conforme a Figura 2. Neste trabalho pode-se notar um grande trecho do Rio Jacuí, entre outros rios importantes, e consequentemente significativos pontos de inundação em diversos locais, tanto dos rios, quanto de lagos, lagunas e açudes.

Devido à escala, consegue-se pontuar diversos municípios, apresentam-se as principais estradas federais e estaduais pode-se observar o Lago Guaíba por inteiro, e uma boa porçấo da Laguna dos Patos. 


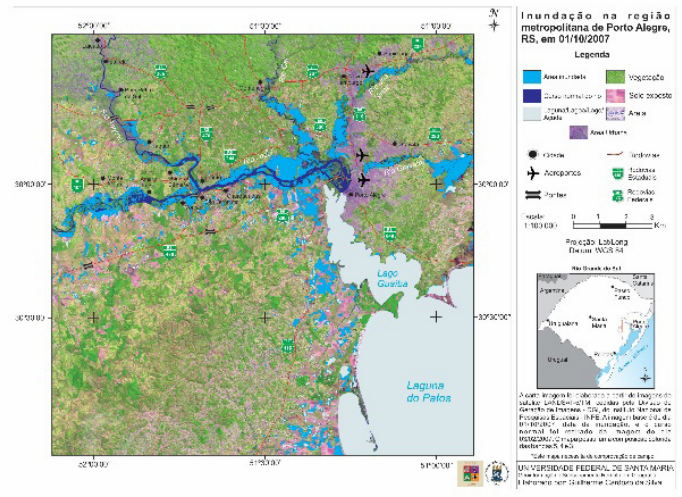

Figura 2 - Padronização para carta-imagem emergencial de inundação em escala média

Para apresentar outra percepção, realizou-se um mapeamento também em escala média, mas desta vez significativamente maior, 1:40.000, do mesmo local, a regiáo metropolitana de porto Alegre. Para tanto, utilizou-se novamente de uma imagem da página do DGI-INPE, mas desta vez do satélite LANDSAT-7, sensor ETM+. A segunda carta-imagem foi realizada com imagem dos dias 25/09/2002 (data da inundação) e 23/07/2002 (curso normal). A partir destas imagens pode-se realizar uma proposta de padronização cartográfica para carta-imagem emergencial de inundação em escala maior, 1:40.000. Este resultado está presente na Figura 3.

Nessa legenda além de informaçóes sobre aeroportos, foram representadas também as rodoviárias, hospitais, Defesa Civil, quartel de bombeiros e algumas escolas, já que a escala permitiu este tipo de informação. Também, pelo maior nível de detalhamento, foi possível localizar e inserir o nome de algumas ruas.

Por fim, adicionou-se o elemento "helicóptero" na legenda, fazendo referência ao momento do resgate. Cabe salientar que nem todos os elementos presentes nesse mapa são postos como obrigação, pois mesmo que a ideia do trabalho seja a padronização cartográfica, muitos símbolos sáo colocados como sugestão, e por mais que um mapa seja elaborado em uma escala semelhante, não há necessidade de haver os mesmos elementos.

A localização dos helicópteros no mapa visa mostrar locais adequados para pouso de helicópteros em situação de emergência, visando orientar as açôes de salvamento e resgate e, dependendo da situaçáo, podem ser colocados em outros pontos estratégicos, na tentativa de ajudar as equipes em seu trabalho em campo.

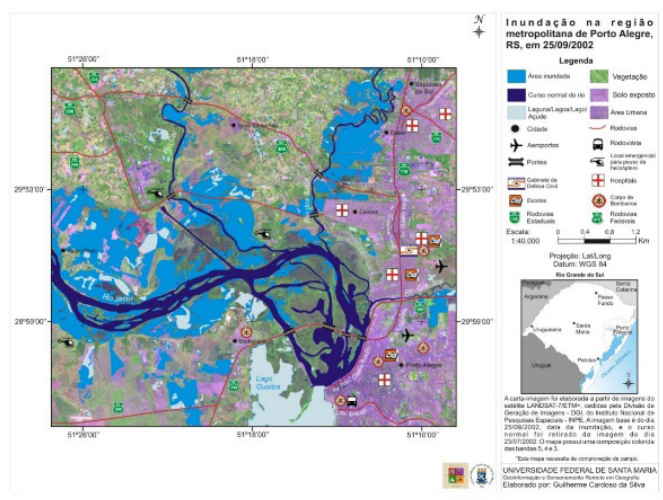

Figura 3 - Padronizaçáo de carta-imagem emergencial de inundaçáo na escala de 1:40.000

É importante que o mapa não perca sua função e permaneça claro e objetivo, além de, evidentemente, obedecer às normas cartográficas. Desta forma haveria um equilíbrio entre a cartografia e a liberdade do cartógrafo.

Ainda visando à questáo das escalas, foi definida a elaboração de uma proposta para mapa de inundação em escala pequena, para isto utilizou-se as imagens MODIS, e definiu-se o estado do Rio Grande do Sul como área teste.

Esta proposta de carta-imagem foi elaborada com uma imagem do dia 29/11/2009, referente a um evento de inundação, sendo esta a imagem base do trabalho, e outra do dia 31/09/2009, na qual que foi delimitado o curso dos rios em seu período de normalidade. Em ambas as imagens foram utilizadas a composiçáo colorida com as bandas 7 (R), 2 (G) e 4 (B).

A terceira e última proposta foi a que mais se diferenciou das demais. Isso se deve ao fato de ter sido utilizada uma escala pequena, de 1:500.000. Devido à resolução espacial de $250 \mathrm{~m}$ das imagens MODIS, este último mapa apresenta menos detalhes, mas em compensação abrange uma área muito maior (Figura 4). Assim, foi representado o Estado do Rio Grande do Sul, tendo como base uma grande inundação ocorrida no ano de 2009.

Percebeu-se que, para não poluir a carta-imagem, dever-se-ia utilizar apenas as BRs, já que a representação também das estaduais poderia tirar um pouco o foco do trabalho, dificultando a visualização da temática principal do mapa, que é a inundação. Também se optou por não utilizar símbolo que indicasse as rodoviárias, pois em um mapa em escala pequena, com tantos municípios, náo haveria a possibilidade de colocar as rodoviárias de tantas cidades, já que sobrecarregaria o mapa e 
dificultaria a visualização do tema principal.

Optou-se pela representaçấo dos aeroportos, que seria útil para mapas emergenciais de inundação, por exemplo, e um número bem menor de municípios no Estado possuem aeroportos, se comparado a rodoviárias, não sobrecarregando o mapa com excesso de signos. Este detalhe foi levado em consideração devido a um dos mapas, apresentados aos profissionais que responderam aos questionários, ter uma legenda excessivamente carregada de signos, o que acabou dificultando a identificação da área afetada pela inundação.

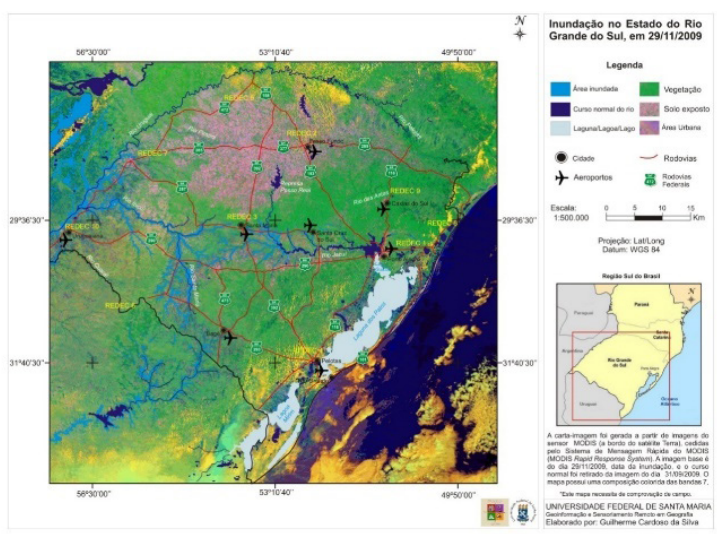

Figura 4 - Proposta de padronização para carta-imagem de inundação em escala pequena

Outra alteração bastante evidente é a apresentação do mapa de apoio. Já que os dois primeiros mapas foram elaborados em escalas médias, o mapa de apoio apresentava o Estado do Rio Grande do Sul, a fim de localizar o leitor cartográfico. Mas como este apresentava todo o Estado, um mapa de apoio que abrange quase a mesma área não seria algo útil na prática. Então, elaborou-se um mapa de apoio que apresenta a Regiáo Sul do Brasil, ou seja, os Estados do Paraná, Santa Catarina e Rio Grande do Sul, além dos países fronteiriços, Uruguai e Argentina.

Foi incluído também um quadrante na cor vermelha para destacar a área abordada no mapa principal, deixando evidente ao leitor a área que se representou a inundação.

Por fim, indicaram-se neste último mapa as Coordenadorias Regionais de Defesa Civil - REDEC, objetivando um complemento, além de também apresentar uma alternativa para este tipo de trabalho. Este não é um elemento obrigatório, ficando a critério do editor cartográfico, de acordo com as necessidades do mapeamento. Esta informação, em específico, pode ser útil para agregar mais uma informação para o profissional que atua em campo, náo prejudicando a clareza e a objetividade do trabalho.

Estas são algumas facilidades que o mapa temático, e principalmente o mapa temático digital, apresenta. As informaçóes podem ser inseridas e retiradas de acordo com as necessidades, desde que as normas cartográficas sejam seguidas, e que se tenha cuidado com a apresentação das informaçóes. Assim, utilizando a mesma base pode-se, com algumas variaçóes na legenda e nos símbolos, elaborar diferentes mapas para serem entregues a diferentes profissionais, tais como do exército, da Defesa Civil, da área da saúde, entre outros.

Com relação às normas cartográficas, e ao que foi discutido em toda a pesquisa, incluindo os mapas avaliados e as respostas dos informantes, percebe-se que as cores precisam ser utilizadas com rigor, sendo o mais coerente possível com o que é estipulado.

Ao usar o vermelho para representar a inundação, pode-se confundir este com outro elemento, como as rodovias, por exemplo, que comumente são representadas por esta cor no âmbito da cartografia topográfica.

O mesmo ocorre com outras cores, como o verde, que é utilizado para vegetaçôes em geral. Se for utilizado para outro elemento, corre-se o risco de confundir o leitor..

Mesmo com o emprego da variação de tons podem ocorrer equívocos. Este trabalho apresenta a proposta da utilizaçáo de tons de azul para distinguir o curso normal das águas, das inundações. Mas dependendo da diferença entre essas cores, pode haver equívocos. $\mathrm{Na}$ presente proposta optou-se por um tom de azul escuro para o curso normal, e um significativamente mais claro para a inundação, julgando uma diferenciação evidente para o profissional que trabalha com este tipo de recurso.

Da mesma forma, utilizou-se um tom ainda mais claro para açudes, lagos, lagunas e lagoas, de acordo com as normas, tendo uma boa diferenciação entre os três tons de azul. Assim, a inundação ficou representada pela mesma cor, quando presente em rios, açudes, lagos, etc.

\section{CONSIDERAÇÓES FINAIS}

A importância da cartografia como ciência hoje é incontestável. Após milhares de anos a sociedade passou por mapas primitivos até chegar à tecnologia da cartografia digital, uso de imagens de satélite, SIG, etc.

Junto a isso, a cartografia organizou uma série de normas que norteiam a elaboração de mapas. Mas mesmo com tamanha evoluçáo da ciência, percebem-se atualmente algumas carências em princípios básicos. 
Com a cartografia digital e seu uso ampliado para representar diversas temáticas, juntamente com o acesso facilitado de computadores e softwares, além do conhecimento em geral, os mapas são gerados dos mais diversos locais, desde empresas (que não se relacionam), até estudantes de graduação, ou curiosos da área. Desta forma, ao obedecer às normas internas e usar da liberdade do editor cartográfico, tem-se uma heterogeneidade significativa nos mapas de uma mesma temática.

Os mapas podem sim apresentar diferentes elementos de acordo com a necessidade de cada trabalho e da situaçáo que está sendo representada. Isso ocorre principalmente devido às particularidades de cada inundação. O que deveria ser evitado, é que os mapeamentos fossem elaborados sem qualquer cuidado, levando exclusivamente em consideração a liberdade do editor cartográfico, sem obedecer às normas cartográficas e a um padrão.

Isto não significa que os mapas de inundação tenham que ser exatamente iguais, apenas levar em consideração um mesmo exemplo, e é neste ponto que a padronização de mapas de inundação viria a colaborar.

No caso dos mapas de inundação, fica evidente que a heterogeneidade dos trabalhos vem a dificultar as análises, atrasando o processo que é de fundamental importância em se tratando de mapas emergenciais, onde a velocidade de atuação é altamente relevante.

Nota-se que os mapas de diferentes instituições não possuem uma preocupação com a compatibilidade de cores e distribuição dos elementos dentro do mapa. Também se percebe que no Brasil muito se deve avançar neste sentido, visto que nem mesmo a terminologia é clara. Por alguns momentos os mapas são citados como meras figuras, o que tira a responsabilidade cientifica do trabalho, mas logo na sequência são intitulados mapas, o que deixa a leitura dúbia.

Os profissionais de diversas áreas que trabalham com cartografia, direta ou indiretamente, se mostram bastantes favoráveis à ideia de uma padronização dos mapas de inundação. Muitos deles citam diversos pontos que merecem uma atençáo especial, seja pela falta de elementos, ou por problemas em sua representação, tais como a falta de clareza e objetividade, e mais especificamente a falta de padráo quanto à localizaçáo dos elementos, terminologia heterogênea e a não utilização de alguns elementos, como título, Norte, mapa de apoio, texto auxiliar, etc.

Se notadas as bases teóricas e as ideias ainda iniciais do trabalho, percebe-se que há forte relevância do objetivo da pesquisa. Ainda ao encontro desta questão, têm-se as análises dos mapas de inundação de diversos locais, que compravam a falta de homogeneidade das legendas.

Para finalizar esta análise, as contribuiçōes dos profissionais foram de grande valia, visto que suas opinióes corroboraram com o que foi visto na literatura e na análise dos mapas prontos. Desta forma, com os questionários, e até mesmo por conversas via e-mail, foi possível acrescentar algumas ideias à pesquisa, o que certamente contribuiu para a proposta da legenda. A proposta de padronização cartográfica para carta-imagem emergencial de inundação visou contribuir para a ciência cartográfica e para a sociedade em geral, visto que o fenômeno de inundação se apresenta com significativa abrangência e frequência em todo o mundo. Percebeu-se que o estabelecimento de um padrão cartográfico para cartas-imagem de inundação é muito importante, utilizando pequenas adaptaçóes de acordo com a escala adotada.

$\mathrm{Na}$ utilização deste tipo de carta em campo, no momento da resposta ao desastre, os profissionais, das mais diversas áreas, poderão compreender de forma mais facilitada o que está representado no papel, ou até mesmo em dispositivos móveis. A função dessa padronização é otimizar o tempo, ou seja, os profissionais já podem imaginar como o mapa será antes mesmo de tê-lo em mãos. A partir disso, o profissional que tem o conhecimento do padrão da cartografia para cartas de inundação, já estará preparado para as cores e localização dos elementos utilizados.

Deste modo, esta pesquisa apresentou uma proposta de padronização cartográfica para carta-imagem emergencial de inundação, com a utilização de imagens de satélite e cartografia digital, a fim de mostrar as vantagens de uma padronização desta temática. Pretendeu-se assim contribuir para o desenvolvimento das atividades atreladas ao mapeamento de áreas inundadas, existindo a possibilidade de trabalhos futuros tanto no aprimoramento desta proposta, como na utilização das ideias para outras temáticas.

\section{REFERÊNCIAS}

ABNT. Associação Brasileira de Normas Técnicas. Folha de desenho - Leiaute e dimensóes. Rio de Janeiro, 1987.

BRASIL, Secretaria de Recursos Humanos. Resolução no 1. Diário Oficial da União, 30 de novembro de 2009.

EM-DAT- The International Disaster Database. Disponível em: <http://www.emdat.be/maps-2007>. Acesso em: 24 junho 2012.

FLEOTIAUX. MNT - Modelo Numérico de Terreno. Re- 
vista Brasileira de Cartografia, Rio de Janeiro, 1987.

International Charter Space Major Disasters. Disponível em: http://www.disasterscharter.org. Acesso em: $15 / 05 / 2013$.

MARCELINO, Emerson Vieira. Desastres naturais e geotecnologias: conceitos básicos. Santa Maria: Instituto Nacional de Pesquisas Espaciais - INPE, 2007.

PARRA, Domingos Filho; SANTOS, João Almeida. Metodologia Científica. São Paulo: Futura, 1998.

PIRES, Carlos Alberto da Fonseca; STRIEDER, Adelir José; DAL'ASTA, Ana Paula. Geoestatística: caderno técnico. Santa Maria: UFSM, CCNE, 2011. X

SANTOS, Suzana Daniela Rocha; HUINCA, Suelen Cristina Movio; MELO, Lineardo Ferreira de Sampaio. Considerações sobre a utilização do pec (padrão de exatidão cartográfica) nos dias atuais. III Simpósio Brasileiro de Ciências Geodésicas e Tecnologias da Geoinformação Recife, 2010.

TOBIN, G. A; MONTZ, B. E. Natural hazards: explanation and integration. New York: The Guilford Press, 1997.

\title{
Correspondência do autor:
}

\author{
Guilherme Cardoso da Silva \\ gcsgeo@gmail.com \\ Tania Maria Sausen \\ sausentaniamaria@gmail.com \\ Andrea Valli Nummer \\ a.nummer@gmail.com
}

ARTIGO RECEBIDO EM: 17/10/2017

REVISADO PELO AUTOR EM: 24/10/2017

ACEITO PARA PUBLICAÇÃO EM:24/10/2017 